\title{
Acute meningoencephalitis associated with SARS-CoV-2 infection in Colombia
}

\author{
María A. Palacio-Toro' ${ }^{1}$ Johan S. Hernández-Botero ${ }^{2,3,8}$. Daniela Duque-Montoya ${ }^{1,2,5}$ - Yuly Osorio ${ }^{6}$. \\ Alejandro Echeverry ${ }^{1} \cdot$ Johanna J. Osorio-Maldonado ${ }^{7} \cdot$ Marcela Orjuela-Rodríguez $^{1,4}$. \\ Alfonso J. Rodríguez-Morales ${ }^{3,9,10}$
}

Received: 25 May 2021 / Revised: 10 September 2021 / Accepted: 21 October 2021 / Published online: 5 November 2021

(c) Journal of NeuroVirology, Inc. 2021

\begin{abstract}
We present the case of a patient in the third decade of life, with asthma as comorbidity, who presented to the emergency department due to odynophagia, dyspnea, and cough of 2 days of evolution, later developing acute ventilatory failure requiring orotracheal intubation. The high-resolution chest tomography study showed consolidation due to a pneumonic process towards the posterior segment of the right lower lobe with areas of ground-glass infiltrates with a peripheral distribution. During the clinical course, the patient presented multiple seizure episodes that met the criteria for status epilepticus with MRI compatible with changes due to leptomeningitis. Given symptoms and thorax imaging, tests for SARS-CoV-2 ensued, with both positive RT-PCR in bronchoalveolar lavage and cerebrospinal fluid for the virus also positive. RT-PCR multiplex panel of meningitis/encephalitis results negative for 14 common organisms. A diagnosis of acute meningoencephalitis associated with COVID-19 was considered, with an adequate response to corticosteroid management; to our knowledge, this is the first adult patient with CNS involvement and CSF positive test in Latin America.
\end{abstract}

Keywords COVID-19 $\cdot$ SARS-CoV-2 $\cdot$ Encephalitis $\cdot$ Seizures $\cdot$ Colombia

Alfonso J. Rodríguez-Morales

alfonso.rodriguez@uam.edu.co;

arodriguezmo@cientifica.edu.pe

1 Universidad de Caldas, Manizales, Caldas, Colombia

2 Grupo de Resistencia Antibiótica de Manizales (GRAM), Manizales, Caldas, Colombia

3 Latin American Network of COVID-19 Research (LANCOVID), Pereira, Risaralda, Colombia

4 Laboratorio de Salud Pública de Caldas, Manizales, Caldas, Colombia

5 Grupo de Neurociencia de Caldas, Manizales, Caldas, Colombia

6 Fundación Universitaria de Ciencias de La Salud, Bogotá, DC, Colombia

7 Universidad del Sinú, Cartagena, Bolivar, Colombia

8 Grupo de Investigación Médica, Escuela de Medicina, Universidad de Manizales, Manizales, Caldas, Colombia

9 Grupo de Investigación Biomedicina, Faculty of Medicine, Fundación Universitaria Autónoma de Las Américas, Risaralda, Pereira, Colombia

10 Master of Clinical Epidemiology and Biostatistics, Faculty of Health Sciences, Universidad Cientifica del Sur, Lima, Peru

\section{Introduction}

The Coronavirus Disease 2019 (COVID-19) pandemic (Dhama et al. 2020) may cause neurological consequences not previously reported (Vargas-Gandica et al. 2020). These features may be a combination of nonspecific complications of systemic disease (Dhama et al. 2020), the effects of direct viral infection, or inflammation of the central nervous system (CNS) and vasculature, which can be para-infectious or post-infectious. Compromise of both the CNS and peripheral nervous systems (PNS) has been demonstrated in patients with severe and non-severe COVID-19 (Ellul et al. 2020).

Although SARS-CoV-2 antigens are detected in different CNS structures, and reactivity by immunohistochemistry in brain sections of autopsies has been reported, the pathophysiology of CNS involvement is still unclear. The endothelial lining of the cerebral vasculature via their angiotensin-converting enzyme (ACE) II receptors tropism or the olfactory nerve, tracts and olfactory striae, towards the piriform cortex are considered as the main possible entry routes (Davies et al. 2020).

On March 4, 2020, at Beijing, China, the first case of CNS involvement with cerebrospinal fluid (CSF) positive 
for SARS-CoV-2 by sequencing was confirmed (Zhang et al. 2020). As the COVID-19 pandemic progressed, laboratory data showed that the overall yield of RT-PCR in CSF was low, and, despite many patients exhibiting signs of CNS involvement, most test were negative, making the diagnosis challenging. The detection of SARS-CoV-2 in CSF is relevant due to the steroids use as part of the standard management, which may be contraindicated in other conditions requiring antimicrobial therapy. We described a case of meningoencephalitis with positive CSF for SARS-CoV-2 in Colombia.

\section{Case}

We present the case of a 26-year-old female health worker with a history of asthma, who presented odynophagia, dyspnea, and cough in the last day before admission, without symptoms improvement using salbutamol (Fig. 1). The next day, she arrived at the emergency department due to selflimited diarrhoea and worsening respiratory symptoms. She was admitted with bronchial obstruction, desaturation, and tachycardia. Chest X-ray showed bronchoalveolar opacities mainly at the right base, with metabolic acidosis, severe oxygenation impairment, and leukocytosis. She developed type I ventilatory failure and was referred to the Intensive Care Unit (ICU). In Fig. 1, a timeline of the main events of the case is presented, including the major clinical findings, studies and management.

At $23 \mathrm{~h}$ in ICU, without a prior history of seizures or epilepsy, the first episode of tonic posture and clonic movements of four limbs ensued without sphincter relaxation and was controlled with midazolam. A simple brain MRI with contrast showed postictal oedema (Fig. 2), and a CSF sample was consistent with an inflammatory profile (Table 1). Given no other explanation for the patient illness and new convulsive episodes with CSF changes (pleocytosis and hyperglycorrhachia), SARS-CoV-2 infection was assessed. New samples from bronchoalveolar lavage and CSF were drawn for RT-PCR analysis (Table 1) plus MRI of CNS and thorax CT-scans (Fig. 2), resulting positive for SARS-CoV-2 (Table 1). This RT-PCR test for SARS-CoV-2 detection uses the primers and probes of the Charite Berlin protocol (Germany) for RdRp and E genes identification (Corman et al. 2020). Additionally, it detects the nucleocapsid gene using the primers and probes proposed in the China Centers for Disease Control and Prevention (CDC) protocol (China CDC 2020).

Dexamethasone $8 \mathrm{mg}$ every $6 \mathrm{~h}$ was initiated and received for 5 days. MRI results show generalized cortical edema, while pulmonary CT scan revealed pneumonic opacities at the right base with a ground-glass pattern. In the next few days, the patient continued improving oxygenation parameters, with lowering of severity markers and inflammation. As the corticosteroid therapy concluded, sedation and
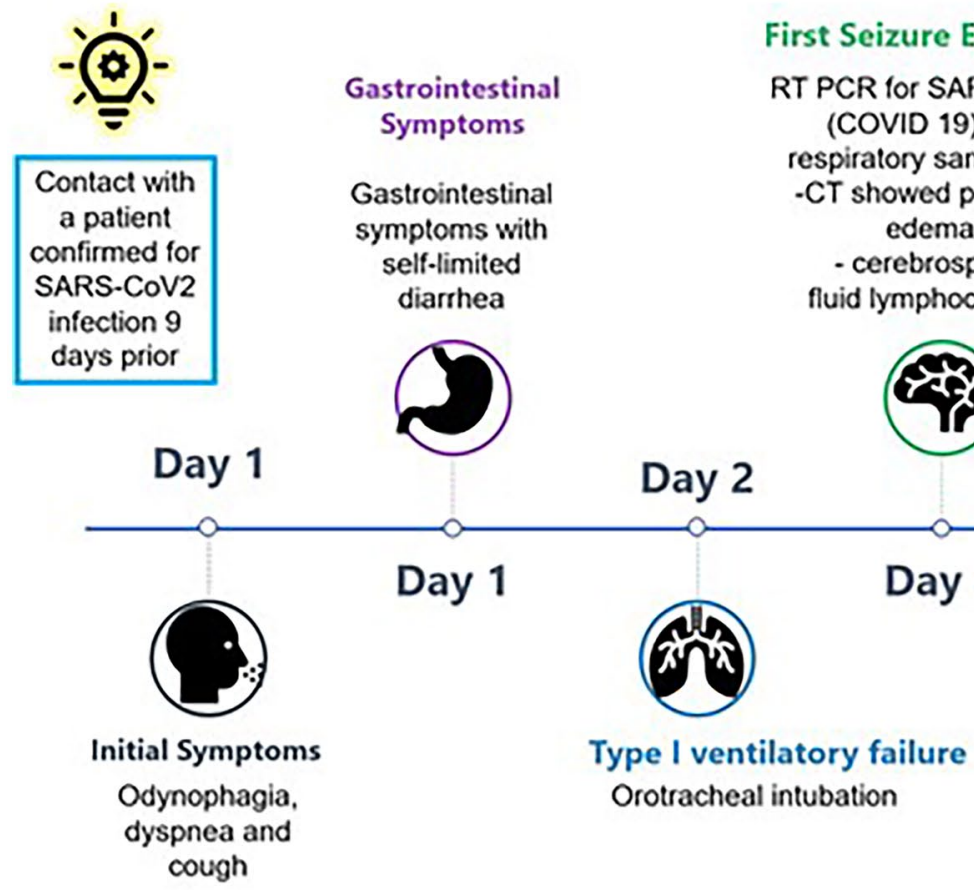

First Seizure Episode

Gastrointestinal Symptoms

Gastrointestinal symptoms with self-limited diarrhea

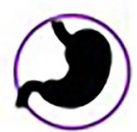

RT PCR for SARS Cov 2 (COVID 19) in a respiratory sample (-) -CT showed postictal edema - cerebrospinal fluid lymphocytosis

\section{Complementary Studies}
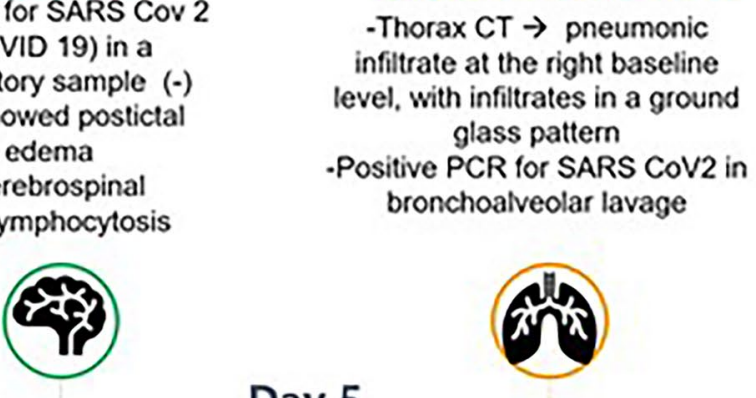

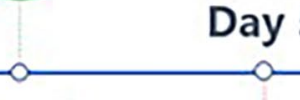

Day 5

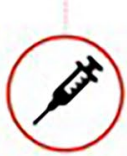

New convulsive event

Dexamethasone IV

- MIR $\rightarrow$ Leptomeningitis associated

with generalized cortical edema

- Cerebrospinal fluid positive RT PCR for SARS Cov 2

Fig. 1 Timeline of the case 
Fig. 2 Simple brain MRI with contrast showing postictal oedema (A), and thorax CTscans of the patient $(\mathbf{B})$

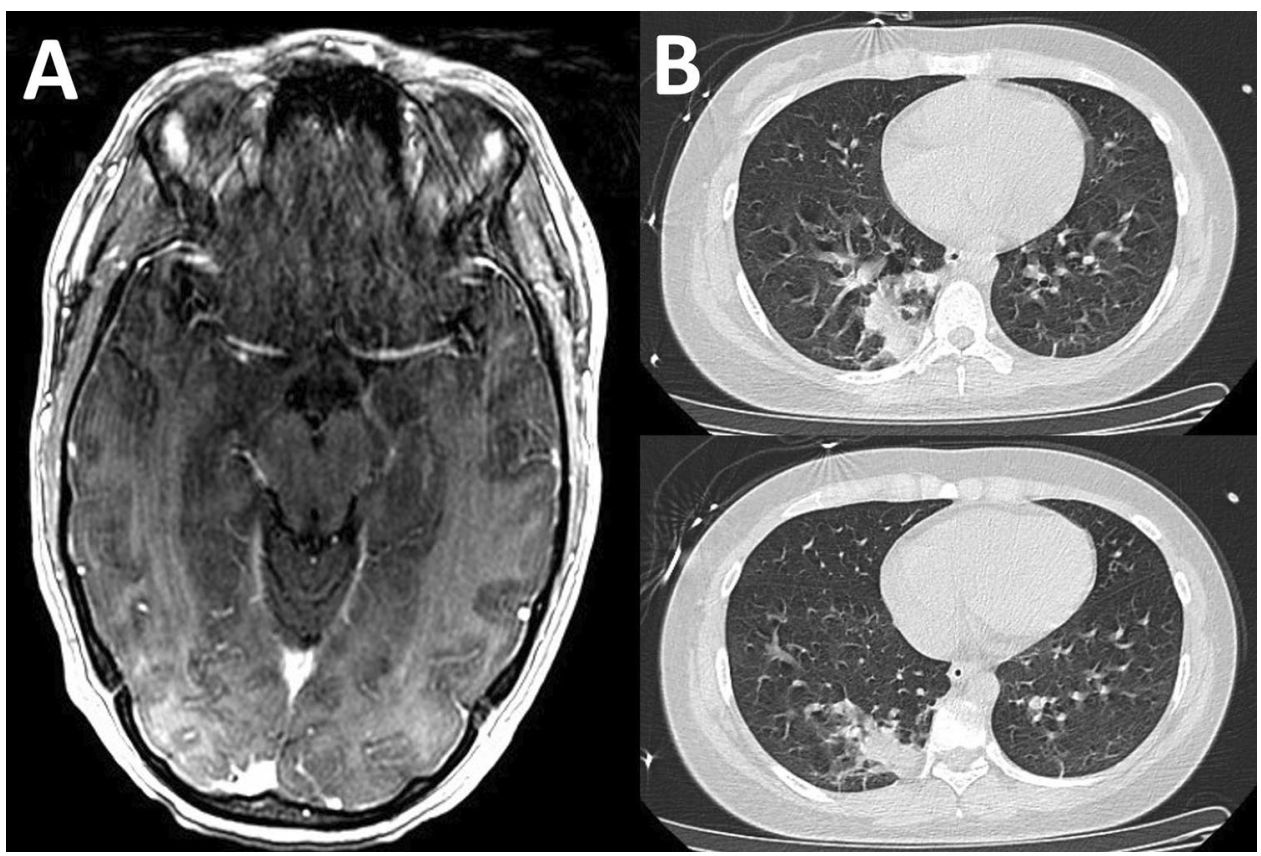

antiepileptics were withdrawn with no seizures and adequate clinical evolution, being discharged after 34 days of hospitalization (a total of 11 days at the ICU). The rehabilitation process began with overall good results. A follow-up electroencephalogram after 1 month of discharge showed normal findings (Fig. 3).

\section{Discussion}

Increasing evidence shows that neurotropism is a common feature of human CoVs, such as HCoV-229E, HCoV-OC43, but also SARS-CoV, MERS-CoV and SARS-CoV-2 (Pene et al. 2003). Viral antigens are detected in the brain stem; the infected regions included the nucleus of the solitary tract and the nucleus ambiguus. In our case, although SARS-CoV-2 was not detected on a pathological tissue from $\mathrm{CNS}$, no other infectious agent was identified, and the SARS-CoV-2 RNA was detected in CSF, we presume this to be the causative agent. Recent findings suggest that severity and mortality may be due to dysfunction of the cardiorespiratory centre in the brainstem (Pene et al. 2003). Neurological symptoms can be divided into 3 categories (Mao et al. 2020): CNS signs and symptoms: headache, vertigo, altered consciousness, ataxia, seizure, stroke; peripheral nervous system signs and symptoms: hypogeusia, hyposmia, neuralgia/neuropathy, Guillain Barre syndrome; and symptoms of skeletal muscle injury: Myalgia + Elevated CPK levels $>200$ U/L.

Three radiological patterns are described in severe COVID-19 infection at the CNS level: signal abnormalities located in the medial temporal lobe, non-confluent multifocal white matter (WM) hyperintense lesions on FLAIR and diffusion with variable enhancement, associated with extensive and isolated WM microhaemorrhages (Kremer et al. 2020).

Regarding meningoencephalitis, this is associated with headache, fever and nuchal stiffness. Encephalitis corresponds to the underlying involvement of the brain parenchyma, including behavioural changes, neurological targeting, altered state of consciousness, and seizures. The CSF shows hyperproteinrrachia, pleocytosis, and euglycorrhachia (Kremer et al. 2020). A study on CSF samples during the beginning of the France COVID-19 epidemic (Destras et al. 2020) showed a low proportion of SARS-CoV-2 positive patients $(2 / 622)$, with high viral loads $(\mathrm{Ct}$ value $<25)$ at respiratory samples, but low load in CSF. By ruling-out blood contamination by traumatic lumbar puncture in a high viral load pneumonia setting (Faico-Filho et al. 2020), the diagnosis of SARS-CoV-2 invasion of the CNS is plausible. In most meningoencephalitis, a high load, particularly in blood, is a prerequisite of direct invasion of the CNS; hence, in our patient, the coincidence of both is consistent. As most reports coincide, the CNS pathogenesis in COVID19 is more directly related to the immune response than for a direct neural cytopathic effect (Lucchese 2020). In Latin America, only one report from Argentina described the presence of SARS-CoV-2 in a CSF sample (Mohammadi et al. 2020).

The importance of clinically suspected SARS-CoV-2 infection in people at high risk, such as healthcare workers, is highlighted. In the presence of initial tests performed by negative nasopharyngeal swab, if the clinical suspicion is high and the existence of a false negative is possible, and there is extrapulmonary involvement (as in the 
Table 1 Laboratory findings of the patient

\begin{tabular}{|c|c|c|}
\hline Test & Finding & Reference values \\
\hline \multicolumn{3}{|l|}{ Cerebrospinal fluid } \\
\hline Aspect & Transparent & \\
\hline $\mathrm{pH}$ & 8.0 & \\
\hline Density $(\mathrm{g} / \mathrm{mL})$ & 1.015 & $1.0063-1.0075$ \\
\hline Glucose (mg/dl) & 90.7 & $40-70$ \\
\hline Proteins (mg/dL) & 32.3 & $15-45$ \\
\hline Leukocytes (cells/mL) & 34 & $0-8$ \\
\hline Neutrophils (\%) & 50 & \\
\hline Lymphocytes (\%) & 50 & \\
\hline Red blood (cells) & 0 & \\
\hline \multicolumn{3}{|l|}{ Multiplex PCR meningeal panel } \\
\hline Cryptococcus neoformans/C. gattii & Negative & Negative \\
\hline Escherichia coli $\mathrm{K} 1$ & Negative & Negative \\
\hline Haemophilus influenzae & Negative & Negative \\
\hline Listeria monocytogenes & Negative & Negative \\
\hline Neisseria meningitidis & Negative & Negative \\
\hline Streptococcus agalactiae & Negative & Negative \\
\hline Streptococcus pneumoniae & Negative & Negative \\
\hline Cytomegalovirus & Negative & Negative \\
\hline Enterovirus & Negative & Negative \\
\hline Herpes simplex virus 1 & Negative & Negative \\
\hline Herpes simplex virus 2 & Negative & Negative \\
\hline Human herpes virus 6 & Negative & Negative \\
\hline Human parechovirus & Negative & Negative \\
\hline Varicella zoster virus & Negative & Negative \\
\hline \multicolumn{3}{|c|}{ RT-qPCR* for SARS-CoV-2 at samples from } \\
\hline Bronchoalveolar lavage & Positive, $\mathrm{Ct}<25$ & Negative \\
\hline Cerebrospinal fluid & Positive, $\mathrm{Ct}>36$ & Negative \\
\hline
\end{tabular}

*Samples for RT-qPCR were processed by an in-house protocol in the departmental public health laboratory, "Caldas Protocol," validated by the National Institute of Health of Colombia for COVID-19 laboratory confirmation. The test evaluated the presence of E, N, RdRp SARS-CoV-2 genes in the CFX96 Touch ${ }^{\text {TM }}$ BIORAD RT-PCR system after sample quality controls and RNA extraction. The positive RTqPCR for SARS-CoV-2 in bronchoalveolar lavage by amplification of the three genes (RdRp, $\mathrm{N}$ y E) in both replicates confirmed the diagnosis of COVID-19 pneumonia with a high viral load according to a cycle threshold $(\mathrm{Ct})<25$ for all genes. CSF preanalytical steps in both duplicates result in an RNA concentration of $13.6 \mathrm{ng} / \mu \mathrm{L}$ with a ratio $260 / 280$ of 1.8 deem adequate for downstream analysis. CSF was positive for SARS-CoV-2 in both duplicates with a late $\mathrm{Ct}$ value for $\mathrm{N}$ gene $(\mathrm{Ct}>36)$; cytochemical analysis of sample revealed no red blood cells in CSF; hence, traumatic lumbar puncture was ruled out present case, the CNS), a differential diagnosis should be considered for meningeal infection by another pathogen. Once this is ruled out, SARS-CoV-2 should be assessed. Although CSF can be negative, testing SARS-CoV-2 at bronchoalveolar lavage samples is relevant (Patrucco et al. 2020; Taton et al. 2020). The detection of SARS-CoV-2 in the CSF by PCR or the evaluation of intrathecal antibodies' synthesis seems to be uncommon; less than $7 \%$ of the tests performed were positive in patients with neurological manifestations (Lewis et al. 2021).

Most COVID-19 patients with meningoencephalitis improved after corticosteroid treatment (Huo et al. 2021).
Considering SARS-CoV-2 at the CSF as part of the differential diagnosis is key before beginning intravenous corticosteroids. When upper respiratory samples are negative, low respiratory tract samples are unavailable, and there is no other pathogen that explains the neurological signs and symptoms, CSF should be processed for a high sensibility RT-qPCR assay (three gene targets, sensibility 100\%) for SARS-CoV-2 detection (Etievant et al. 2020). When ruling out other causes, it is prudent to consider testing for SARS-CoV-2 also in bronchoalveolar lavage. Such samples are sensitive for SARS-CoV-2 infection (Mohammadi et al. 2020). 


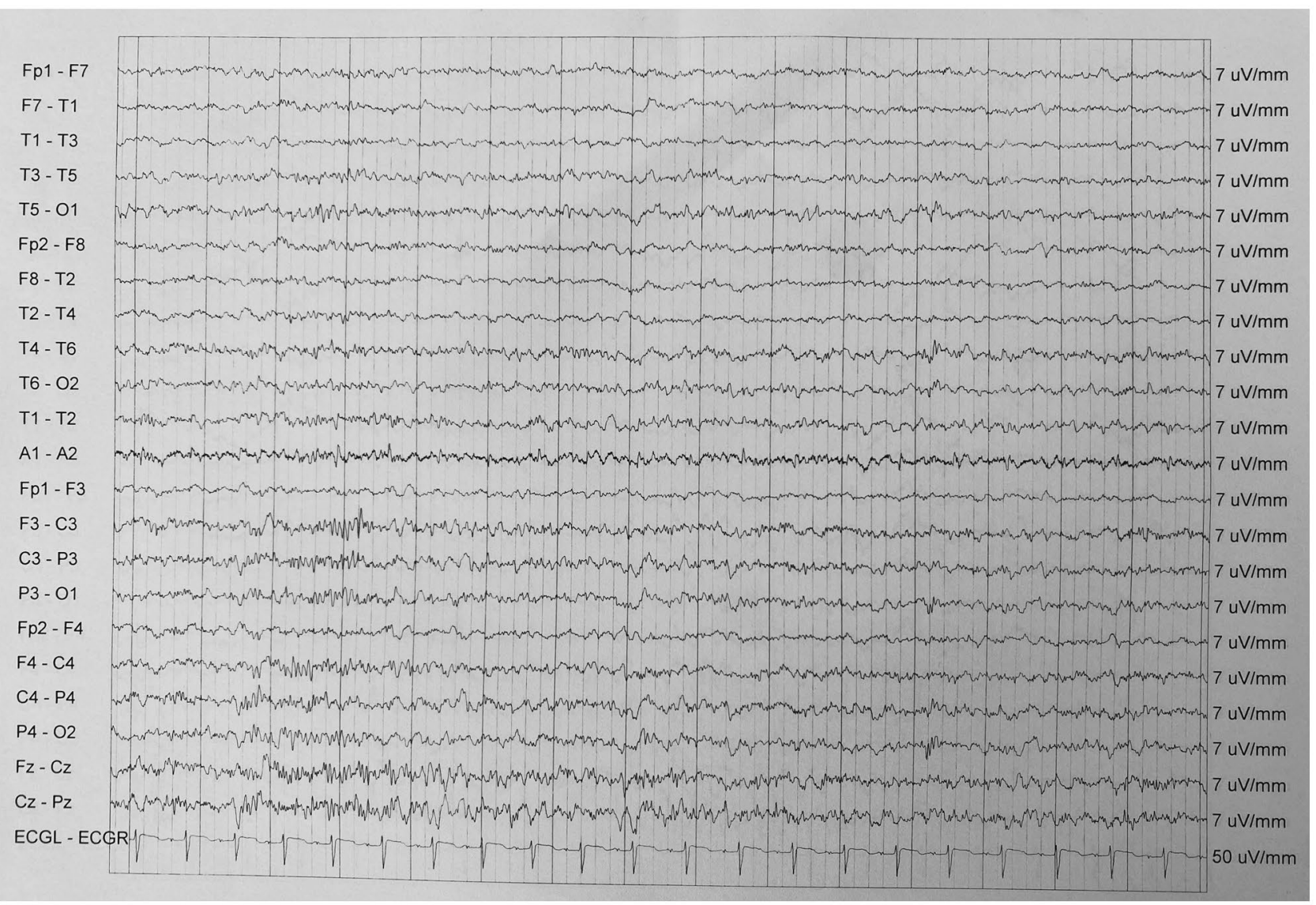

Fig. 3 Electroencephalogram of the patient at a follow-up, at 1 month after discharge

This case is relevant because it shows that the unconscious patients in the current context are potentially infected by SARS-CoV-2, as presumed. To end the pandemic of SARS-CoV-2/COVID-19, its diagnosis must be prompt and not overlook any findings. It should be kept in mind that encephalitis symptoms may be the first indication to find the hidden SARS-CoV-2 infection in some patients.

Author contribution MAPT, JSHB, DDM, and AJRM conceived the report. YO, DDM, AE, JJOM, collected data, analysed and interpreted clinical data. MOR analysed CSF with RT-PCR for SARS-CoV-2 diagnosis. JSHB, DDM, AJRM wrote the first draft. JSHB, DDM, AJRM, reviewed the literature. All authors approved the subsequent draft versions. All authors approved the final submitted version.

\section{Declarations}

Ethics approval and consent to participate Written consent from the patient was obtained for publication.

Conflict of interest We declare that we have no competing interests, except that the first author is the reported case.

\section{References}

China CDC (2020). Centers for Disease Control and Prevention. China CDC Primers and Probes for Detection 2019-nCoV. Available online http://ivdc.chinacdc.cn/kyjz/202001/t20200121_211337. html (accessed on 24 Aug 2021)

Corman V, Bleicker T, Brünink S, Drosten C, Zambon M (2020) Diagnostic detection of 2019-nCoV by real-time RT-PCR. World Health Organization 17:1-13

Davies J, Randeva HS, Chatha K, Hall M, Spandidos DA, Karteris E, Kyrou I (2020) Neuropilin1 as a new potential SARSCoV2 infection mediator implicated in the neurologic features and central nervous system involvement of COVID19. Mol Med Rep 22:4221-4226

Destras G, Bal A, Escuret V, Morfin F, Lina B, Josset L (2020) Systematic SARS-CoV-2 screening in cerebrospinal fluid during the COVID-19 pandemic. The Lancet Microbe 1:e149

Dhama K, Khan S, Tiwari R, Sircar S, Bhat S, Malik YS, Singh KP, Chaicumpa W, Bonilla-Aldana DK, Rodriguez-Morales AJ (2020) Coronavirus disease 2019-COVID-19. Clin Microbiol Rev 33

Ellul MA, Benjamin L, Singh B, Lant S, Michael BD, Easton A, Kneen R, Defres S, Sejvar J, Solomon T (2020) Neurological associations of COVID-19. Lancet Neurol 19:767-783

Etievant S, Bal A, Escuret V, Brengel-Pesce K, Bouscambert M, Cheynet V, Generenaz L, Oriol G, Destras G, Billaud G, Josset L, Frobert E, Morfin F, Gaymard A (2020) Performance assessment 
of SARS-CoV-2 PCR assays developed by WHO referral laboratories. J Clin Med 9

Faico-Filho KS, Passarelli VC, Bellei N (2020) Is higher viral load in SARS-CoV-2 associated with death?. Am J Trop Med Hyg 103:2019-2021

Huo L, Xu KL, Wang H (2021) Clinical features of SARS-CoV2-associated encephalitis and meningitis amid COVID-19 pandemic. World J Clin Cases 9:1058-1078

Kremer S, Lersy F, de Seze J, Ferre JC, Maamar A, Carsin-Nicol B, Collange O, Bonneville F, Adam G, Martin-Blondel G, Rafiq M, Geeraerts T, Delamarre L, Grand S, Krainik A, Caillard S, Constans JM, Metanbou S, Heintz A, Helms J, Schenck M, Lefebvre N, Boutet C, Fabre X, Forestier G, de Beaurepaire I, Bornet G, Lacalm A, Oesterle H, Bolognini F, Messie J, Hmeydia G, Benzakoun J, Oppenheim C, Bapst B, Megdiche I, Henry Feugeas MC, Khalil A, Gaudemer A, Jager L, Nesser P, Talla Mba Y, Hemmert C, Feuerstein P, Sebag N, Carre S, Alleg M, Lecocq C, Schmitt E, Anxionnat R, Zhu F, Comby PO, Ricolfi F, Thouant P, Desal H, Boulouis G, Berge J, Kazemi A, Pyatigorskaya N, Lecler A, Saleme S, Edjlali-Goujon M, Kerleroux B, Zorn PE, Matthieu M, Baloglu S, Ardellier FD, Willaume T, Brisset JC, Boulay C, Mutschler V, Hansmann Y, Mertes PM, Schneider F, Fafi-Kremer S, Ohana M, Meziani F, David JS, Meyer N, Anheim M, Cotton F (2020) Brain MRI findings in severe COVID-19: a retrospective observational study. Radiology 297:E242-E251

Lewis A, Frontera J, Placantonakis DG, Lighter J, Galetta S, Balcer L, Melmed KR (2021) Cerebrospinal fluid in COVID-19: a systematic review of the literature. J Neurol Sci 421:117316

Lucchese G (2020) Cerebrospinal fluid findings in COVID-19 indicate autoimmunity. Lancet Microbe 1:e242
Mao L, Jin H, Wang M, Hu Y, Chen S, He Q, Chang J, Hong C, Zhou Y, Wang D, Miao X, Li Y, Hu B (2020) Neurologic manifestations of hospitalized patients with coronavirus disease 2019 in Wuhan, China. JAMA Neurol 77:683-690

Mohammadi A, Esmaeilzadeh E, Li Y, Bosch RJ, Li JZ (2020) SARSCoV-2 detection in different respiratory sites: a systematic review and meta-analysis. EBioMedicine 59:102903

Patrucco F, Albera C, Bellocchia M, Foci V, Gavelli F, Castello LM, Bellan M, Sainaghi PP, Airoldi C, Balbo PE, Solidoro P (2020) SARS-CoV-2 detection on bronchoalveolar lavage: an Italian multicenter experience. Respiration 99:970-978

Pene F, Merlat A, Vabret A, Rozenberg F, Buzyn A, Dreyfus F, Cariou A, Freymuth F, Lebon P (2003) Coronavirus 229E-related pneumonia in immunocompromised patients. Clin Infect Dis 37:929-932

Taton O, Papleux E, Bondue B, Knoop C, Van Laethem S, Bauler A, Martiny D, Montesinos I, Delforge ML, Elmaouhab K, Leduc D (2020) Role of the bronchoalveolar lavage in noncritically Ill patients during the SARS-CoV-2 epidemic. Pulm Med 2020:9012187

Vargas-Gandica J, Winter D, Schnippe R, Rodriguez-Morales AG, Mondragon J, Escalera-Antezana JP, Trelles-Thorne MDP, Bonilla-Aldana DK, Rodriguez-Morales AJ, Paniz-Mondolfi A (2020) Ageusia and anosmia, a common sign of COVID-19? A case series from four countries. J Neurovirol 26:785-789

Zhang M, Zhou L, Wang J, Wang K, Wang Y, Pan X, Ma A (2020) The nervous system - a new territory being explored of SARS-CoV-2. J Clin Neurosci 82:87-92

Publisher's Note Springer Nature remains neutral with regard to jurisdictional claims in published maps and institutional affiliations. 